\title{
Magmatism at oceanic core complexes on the ultraslow Southwest Indian Ridge: insights from near-seafloor magnetics
}

Fei Zhou ${ }^{1}$, Jérôme Dyment ${ }^{1 *}$, Chunhui Tao ${ }^{2 *}$, Tao Wu ${ }^{2}$

${ }^{1}$ Université de Paris, Institut de physique du globe de Paris, CNRS, F-75005 Paris, France

${ }^{2}$ Key Laboratory of Submarine Geosciences, MNR, Second Institute of Oceanography, MNR, 310012 Hangzhou, China

\section{SUPPLEMENTARY INFORMATION}

\section{A) Supplementary figures}

These figures complement Figure 1 by showing a more general bathymetric view and structural interpretation of the study areas (Fig. DR1); AUV tracks, magnetic anomaly along tracks, and interpretation of magnetic anomalies (Fig. DR2); and intermediate stages in the analysis of the magnetic anomalies (Fig. DR3). 

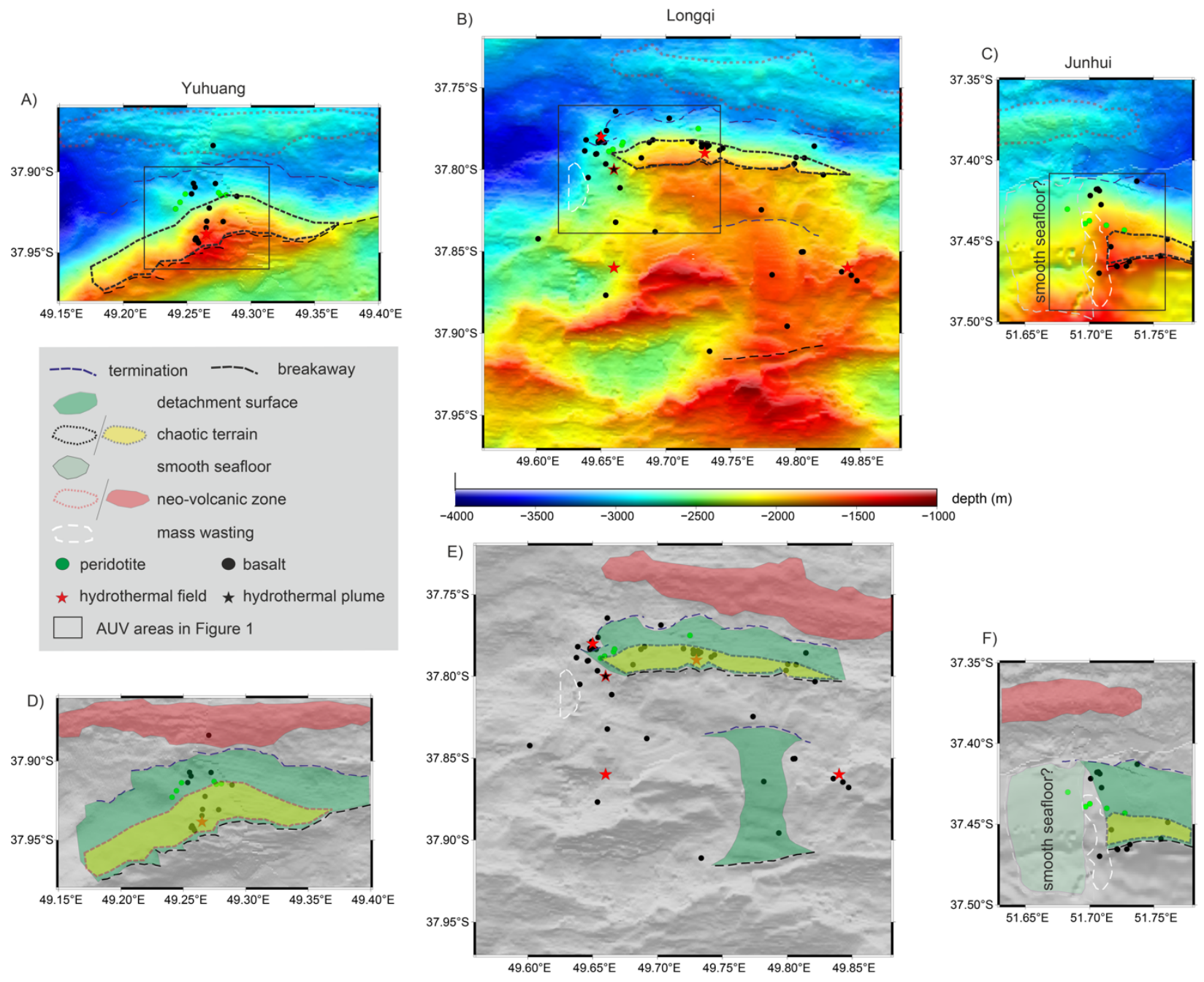

Figure DR1. Regional bathymetry (top) and structural interpretation (bottom) of three OCCs. The red contour dotted lines (top) and red patterns (bottom) represent the neo-volcanic zones, the black dashed lines the breakaways, the blue dashed lines the terminations, the black solid circles show the location of dredged basalt samples and the green circles the location of dredged serpentinite samples. The red stars mark the location of known hydrothermal fields and the black star is a hydrothermal field inferred from turbidity anomalies. The green patterns (bottom) underline the detachment footwall from termination to breakaway; the white patterns (bottom) the mass wasting structures; the black dotted lines (top) and the yellow pattern (bottom) the chaotic terrain; and the light green pattern (bottom) the inferred smooth seafloor. The black boxes show the AUV study areas. 

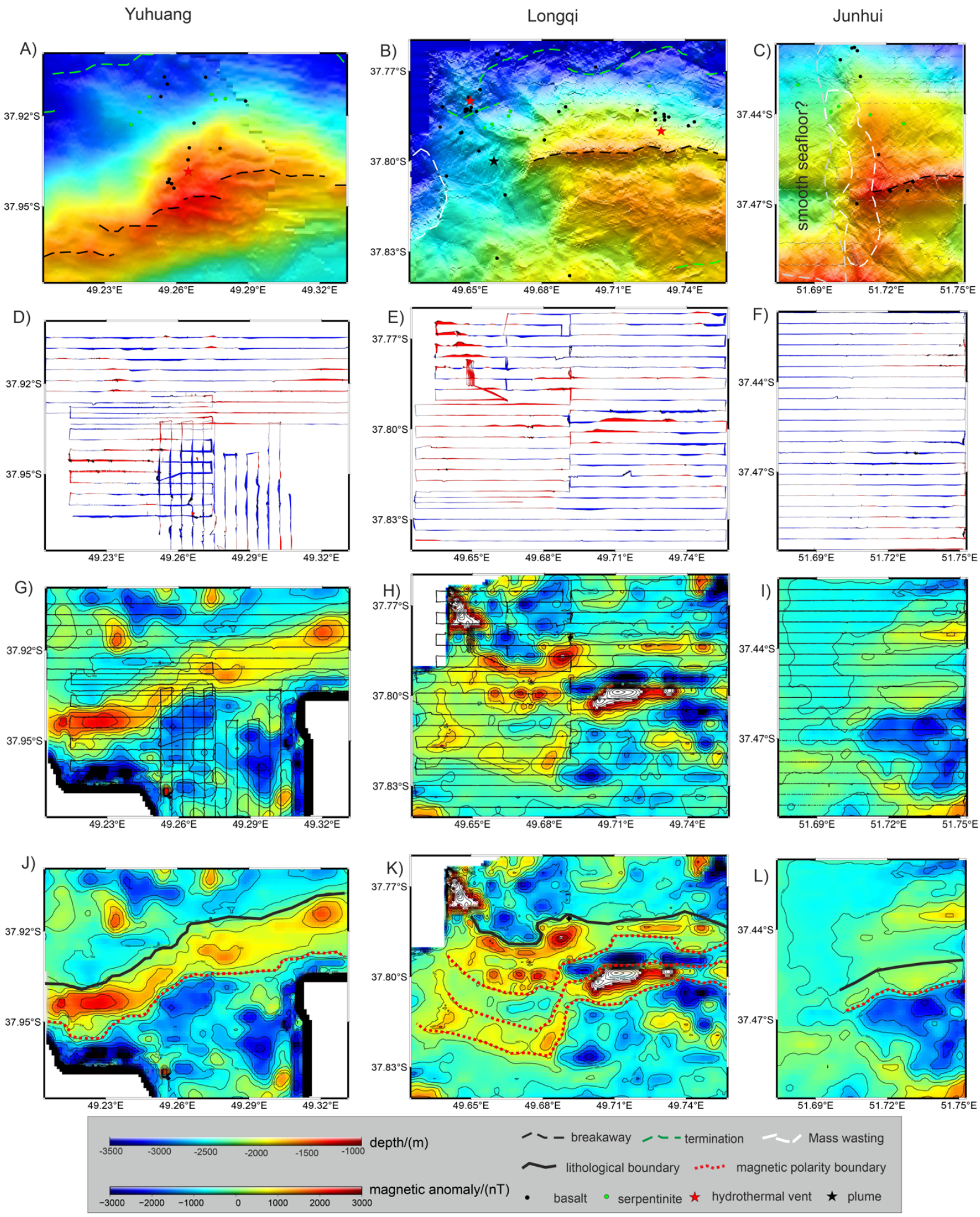

Figure DR2. A-C, local 2D high-resolution bathymetry map with structural interpretation as on Figure DR1. D-F, magnetic anomalies along tracks (red positive, blue negative). G-I, Gridded Reduced-To-the-Pole (RTP) magnetic anomalies overlain by AUV tracks. J-L, interpretation of RTP magnetic anomalies, the thick black lines represent lithological boundaries between serpentinized peridotite and basalt, the red dashed lines display magnetic polarity boundaries. 

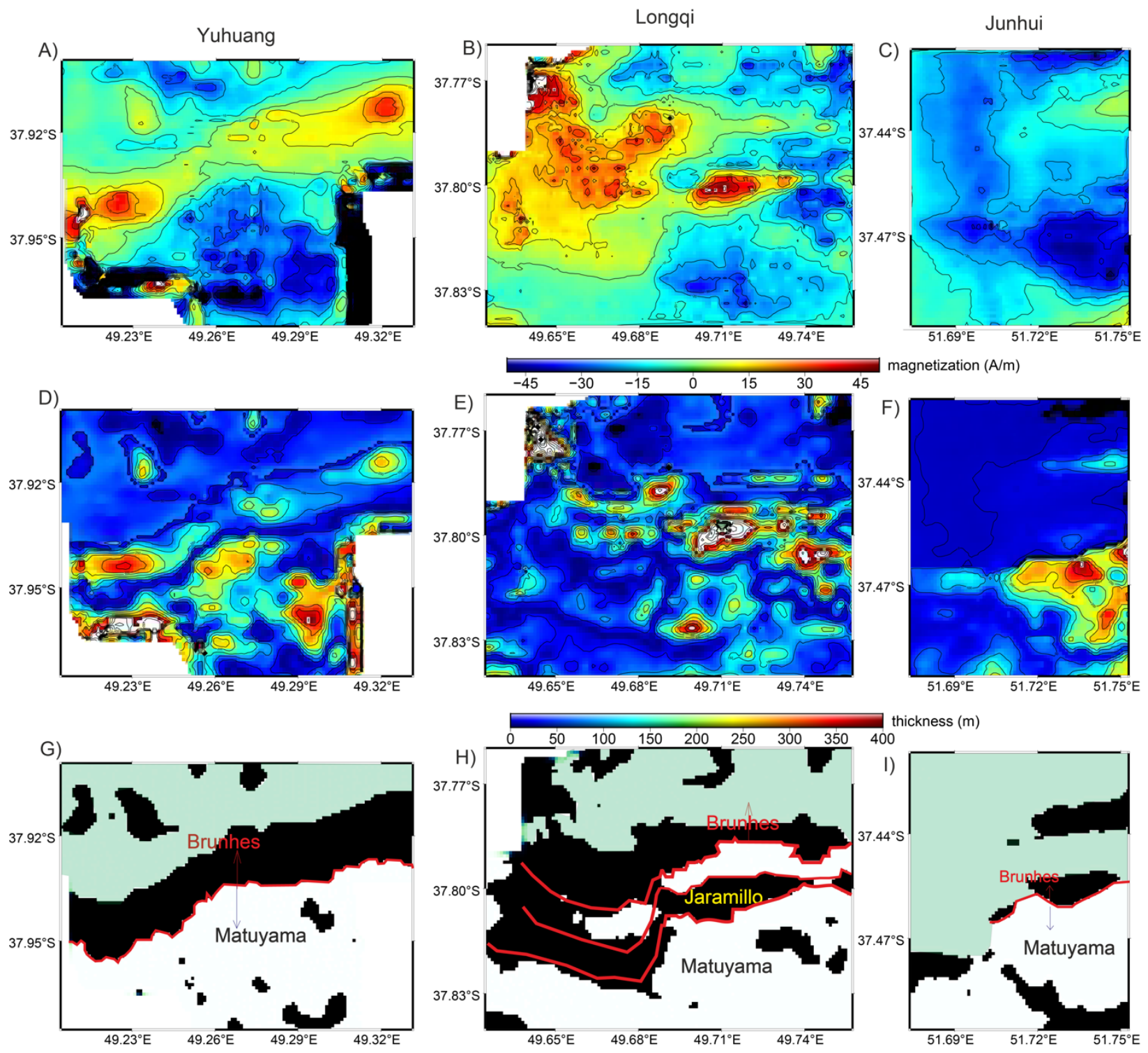

Figure DR3. Intermediate steps to obtain Reduced-To-the-Pole (RTP) magnetic anomaly and Equivalent Thickness of extrusive Basalt (ETB). A-C, Equivalent magnetization, D-F, ETB, and G-I geomagnetic polarity of the extrusive basalt layer considered for the forward modelling of Yuhuang, Longqi, and Junhui areas. The light green patterns show serpentinite which only bears induced magnetization. 


\section{B) Mathematics of inversion method}

With the assumption that magnetization in an individual prism is constant, the inversion problem can be described as searching an optimized solution to the linear Euler equation

$$
d=A m
$$

where $d$ is observed magnetic data, $A$ is a linear operator linking the data space and model space, and $m$ is the targeted parameter model. In order to reduce the intrinsic non-uniqueness during the solving process, a regularized objective function is constructed:

$f(m)=\|A m-d\|^{2}+\alpha\left\|W\left(m-m_{0}\right)\right\|^{2}$

$W$ is a smooth constraint weight that is made of finite-difference of every point (Li and Oldenburg, 1996), $\alpha$ is a regularized constant to control the speed of convergence and balance the weight between the misfit function (front panel) and the stable function (latter panel), and $m_{0}$ is an original model that is set up to zero here. The optimized solution is obtained when the objective function reach its minimal value. Solving the inversion problem therefore means finding the minimal value of the objective function,

$$
f(m)=\|A m-d\|^{2}+\alpha\|W m\|^{2}=\min .(3)
$$

To find the optimized $m$ making the objective function minimum, we calculate the derivative of $f(m)$ :

$$
\delta f(m)=2 A^{T}(A m-d)+2 \alpha W^{T} W m=0 .
$$

Then we get a new Euler equation as follow: 


$$
A^{T} d=\left(A^{T} A+\alpha W^{T} W\right) m .
$$

We introduce a new linear operator L

$$
L=A^{T} A+\alpha W^{T} W .(6)
$$

Then the equation (5) is rewritten as:

$$
A^{T} d=\operatorname{Lm}(7)
$$

Thus, equation (7) can be solved with minimal residual iterative schematic

$$
m_{n+1}=m_{n}-k_{n} I_{n} n=0,1,2, \ldots
$$

under the condition that $L$ is a linear positive determined operator and $m$ is a linear Hilbert Space (Zhdanov, 2015). In the formulae (8),

$$
\begin{aligned}
& I_{n}=\left(A^{T} A+\alpha W^{T} W\right) m_{n}-A^{T} d \\
& k_{n}=\frac{\left(I_{n}, L I_{n}\right)}{\left(L I_{n}, L I_{n}\right)}=\frac{\left\|A I_{n}\right\|^{2}+\alpha\left\|W I_{n}\right\|^{2}}{\left\|L I_{n}\right\|^{2}}
\end{aligned}
$$

Other intermediate parameters of the regularized Minimum Residual Method are:

$$
\begin{aligned}
& r_{n}=A m_{n}-d, I_{n}=A^{T} r_{n}+\alpha W^{T} W m_{n}, \\
& g_{n}=A I_{n}, h_{n}=L I_{n}, p_{n}=W I_{n} \\
& k_{n}=\frac{\left\|g_{n}\right\|^{2}+\alpha\left\|p_{n}\right\|^{2}}{\left\|h_{n}\right\|^{2}},
\end{aligned} .
$$

The iterative process is terminated when the misfit reaches the given level $\varepsilon_{0}$ :

$$
\left\|r_{N}\right\|^{2} \leq \varepsilon_{0} .(10)
$$

or when the misfit tends to be stable after several iterations. 


\section{C) Contribution of serpentinite and gabbro to the magnetic anomalies in models}

Some magnetite-rich serpentinite may have a role in shaping marine magnetic anomalies.

Most rock magnetic property studies of dredged or drilled oceanic serpentinite samples, however, emphasize their relatively lower Koenigsberger ratio $(\sim 1)$ with respect to basalt $(>10)$ and therefore the predominance of induced magnetization over remanent magnetization for these samples (e.g., (Oufi, 2002; Maffione et al., 2014; Chen et al., 2021). This observation is further confirmed by the smooth and low amplitude magnetic anomalies observed where serpentinite samples have been dredged in our study areas. Although our knowledge on the serpentinization and the magnetic properties of the newly-formed magnetite remains quite limited, these observations suggest that the slow and progressive alteration of outcropping peridotite does not result in magnetite bearing a significant remanent magnetization but mostly an induced magnetization. Conversely, serpentinites formed at high temperature in highly fractured and permeable environments, such as at hydrothermal sites, do locally exhibit a strong remanent magnetization (e.g., Szitkar and Murton, 2018). The occurrence of such serpentinite is rare and only local. As our study areas do not show any serpentinite-hosted hydrothermal sites, we are not considering a significant remanent magnetization for the serpentinite in our magnetic models. Our simple models do not take into account complexities related, for instance, to variable degrees of serpentinization, and the assumption of a uniform $2 \mathrm{~A} / \mathrm{m}$ induced magnetization for the serpentinite is acknowledgeably a simplification.

Another simplification of our modeling exercise is, it does not consider gabbro as a separate contributor to the magnetic anomalies. The effect of gabbro underlying basalt in the magmatic 
crust just adds a modest contribution to that of basalt and is accounted for in the modeled basalt magnetization. The effect of exhumed gabbro bodies beneath the detachment surface is modelled as if it is due to basalt as well, which somehow accounts for their faster cooling and presumably higher magnetization with respect to the gabbro underlying magmatic crust.

\section{D) A constraint on the absolute remanent magnetization of the extrusive basalt layer}

The forward modeling exercise described in the "Modeling" subsection of the "Results" section was initially attempted with a constant remanent magnetization of extrusive basalt of $8 \mathrm{~A} / \mathrm{m}$, all other parameters being kept similar. It provided reasonable results for the Yuhuang and Junhui OCCs but led to a difficulty on the Longqi OCC, where the very strong anomaly associated to the Jaramillo episode near the breakaway of the OCC could not be accommodated with the given modelling conditions. Assuming an $8 \mathrm{~A} / \mathrm{m}$ remanent magnetization for the basaltic layer in this area requires this layer to be anomalously thick, close to $1000 \mathrm{~m}$, to account separately for either the positive or the negative observed anomalies. However, juxtaposing two thick sources of opposite polarity would result in cancelling out the effects of their deeper part at the observation point on the AUV track, $100 \mathrm{~m}$ above seafloor. Proper modelling of this anomaly requires a basaltic layer not thicker than $500 \mathrm{~m}$, which can only be achieved with a remanent magnetization intensity of at least $15 \mathrm{~A} / \mathrm{m}$, which was finally chosen and presented in Figure 2. It should be noted that the analysis of this anomaly therefore constrains the maximum thickness of the basalt layer on the breakaway associated to the Jaramillo episode on Longqi OCC but also offers a suitable value of the remanent magnetization of basalt for this area. Because the OCCs investigated in this study 
were formed at about the same period, we have no reason to adopt different magnetization intensities and modified our initial hypothesis of $8 \mathrm{~A} / \mathrm{m}$ to $15 \mathrm{~A} / \mathrm{m}$ for all three of them. This particular anomaly therefore offered a mean to constrain the absolute magnetization of basalt in this area given our simplifying assumptions.

\section{E) Amount of extrusive basalt on the three OCCs}

We estimate the amount of extrusive basalt AEB for each area along the representative sections shown in Fig. 2A-C and G-I by dividing the ETB integrated on the section by the length of the

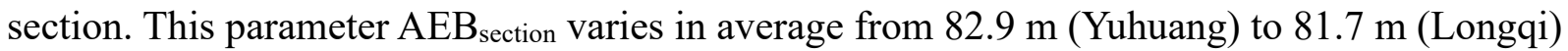
to $52.1 \mathrm{~m}$ (Junhui). However, to alleviate possible local variations on sections, we prefer to estimate the amount of extrusive basalt for each area on the whole grids shown in Fig. 2D-F by dividing the ETB integrated on the grid by the area of the grid. This parameter $\mathrm{AEB}_{\text {grid }}$ varies

from $77.4 \mathrm{~m}$ (Yuhuang) to $68.5 \mathrm{~m}$ (Longqi) to $30.1 \mathrm{~m}$ (Junhui). Both determinations from grids and across-axis sections integrate the processes in time, unlike (for instance) along-axis profiles that would represent snapshots at given (and poorly constrained) times. We consider the value computed from the grid as more representative of the average amount of basalt for each investigated area, and we use the variation among values determined from a series of across-axis sections to estimate the uncertainty. We therefore evaluate the uncertainties on $\mathrm{AEB}_{\text {grid }}$ by computing $\mathrm{AEB}_{\text {section }}$ on the across-axis sections shown in the following figure. The final estimates of $\mathrm{AEB}_{\text {grid }}$ are $77.4 \pm 10.7 \mathrm{~m}$ (Yuhuang), $68.5 \pm 14.2 \mathrm{~m}$ (Longqi), and $30.1 \pm 22.1 \mathrm{~m}$ (Junhui). 

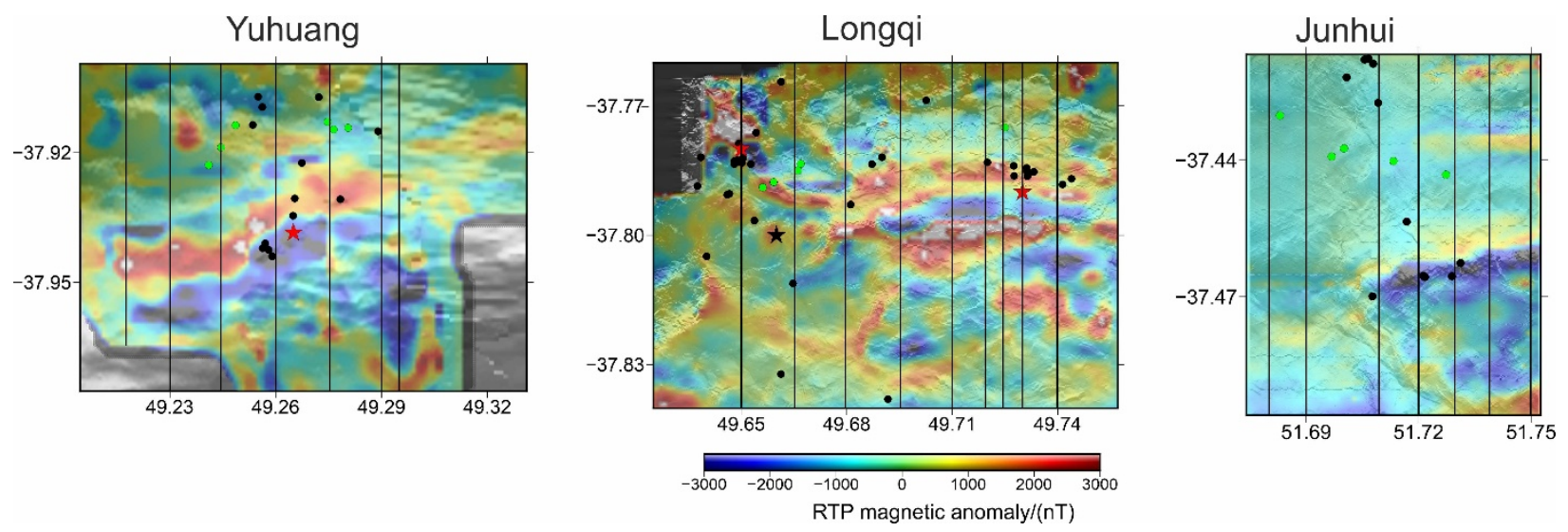

Figure DR4: Location of sections used to compute the $\mathrm{AEB}_{\text {section }}$ taken into account in the estimation of uncertainties on $\mathrm{AEB}_{\text {grid. }}$. 


\section{F) Dredge sample locations}

\begin{tabular}{|c|c|c|c|c|c|c|}
\hline \\
\hline Basalt & $\begin{array}{l}49.255 \\
49.2535 \\
49.2563 \\
49.2445 \\
49.289 \\
49.2568 \\
49.2674\end{array}$ & $\begin{array}{l}-37.9071 \\
-37.9136 \\
-37.9421 \\
-37.9188 \\
-37.9151 \\
-37.942 \\
-37.9224\end{array}$ & $\begin{array}{l}49.2562 \\
49.257 \\
49.2783 \\
49.2722 \\
49.2805 \\
49.257\end{array}$ & $\begin{array}{l}-37.9095 \\
-37.941 \\
-37.9308 \\
-37.9072 \\
-37.9143 \\
-37.941\end{array}$ & $\begin{array}{l}49.2649 \\
49.258 \\
49.241 \\
49.2704 \\
49.259 \\
49.2654\end{array}$ & $\begin{array}{l}-37.9346 \\
-37.9425 \\
-37.9229 \\
-37.8836 \\
-37.944 \\
-37.9306\end{array}$ \\
\hline Serpentinite & $\begin{array}{l}49.2805 \\
49.2445 \\
\end{array}$ & $\begin{array}{r}-37.9143 \\
-37.9188 \\
\end{array}$ & $\begin{array}{l}49.2764 \\
49.241 \\
\end{array}$ & $\begin{array}{r}-37.9147 \\
-37.9229 \\
\end{array}$ & $\begin{array}{l}49.2747 \\
49.2486 \\
\end{array}$ & $\begin{array}{r}-37.9129 \\
-37.9137 \\
\end{array}$ \\
\hline \multicolumn{7}{|l|}{ Longqi } \\
\hline Basalt & $\begin{array}{l}49.6493 \\
49.6482 \\
49.6482 \\
49.6527 \\
49.6537 \\
49.6505 \\
49.7026 \\
49.6613 \\
49.6669 \\
49.7332 \\
49.7275 \\
49.6537 \\
49.7337 \\
\end{array}$ & $\begin{array}{l}-37.7787 \\
-37.783 \\
-37.784 \\
-37.7835 \\
-37.8768 \\
-37.7821 \\
-37.7687 \\
-37.7644 \\
-37.7834 \\
-37.7853 \\
-37.7839 \\
-37.7966 \\
-37.911 \\
\end{array}$ & $\begin{array}{l}49.6502 \\
49.646 \\
49.648 \\
49.648 \\
49.6613 \\
49.6872 \\
49.6917 \\
49.6811 \\
49.6542 \\
49.7414 \\
49.7276 \\
49.6401 \\
49.6592 \\
\end{array}$ & $\begin{array}{l}-37.7832 \\
-37.7906 \\
-37.7828 \\
-37.7835 \\
-37.8322 \\
-37.7835 \\
-37.838 \\
-37.7929 \\
-37.7762 \\
-37.7882 \\
-37.7862 \\
-37.8049 \\
-37.7877\end{array}$ & $\begin{array}{l}49.6466 \\
49.6488 \\
49.648 \\
49.6647 \\
49.6385 \\
49.7314 \\
49.69 \\
49.6375 \\
49.7439 \\
49.72 \\
49.7312 \\
49.7313 \\
49.6488 \\
\end{array}$ & $\begin{array}{l}-37.7904 \\
-37.783 \\
-37.7828 \\
-37.8112 \\
-37.7819 \\
-37.7863 \\
-37.7819 \\
-37.7886 \\
-37.7869 \\
-37.7831 \\
-37.7844 \\
-37.7852 \\
-37.7826 \\
\end{array}$ \\
\hline Serpentinites & $\begin{array}{l}49.6661 \\
49.6561 \\
\end{array}$ & $\begin{array}{l}-37.785 \\
-37.7889\end{array}$ & $\begin{array}{l}49.6669 \\
49.725\end{array}$ & $\begin{array}{l}-37.7834 \\
-37.775\end{array}$ & 49.6592 & -37.7877 \\
\hline Junhui & & & & & & \\
\hline Basalt & $\begin{array}{l}51.7217 \\
51.7312 \\
51.737 \\
51.7554 \\
51.7077\end{array}$ & $\begin{array}{l}-37.4657 \\
-37.4626 \\
-37.4129 \\
-37.4591 \\
-37.4699\end{array}$ & $\begin{array}{l}51.7213 \\
51.7079 \\
51.7008 \\
51.7092 \\
51.7607\end{array}$ & $\begin{array}{l}-37.4654 \\
-37.4188 \\
-37.4218 \\
-37.4274 \\
-37.4489\end{array}$ & $\begin{array}{l}51.7289 \\
51.7168 \\
51.7056 \\
51.7067\end{array}$ & $\begin{array}{l}-37.4655 \\
-37.4535 \\
-37.4179 \\
-37.4177\end{array}$ \\
\hline Serpentinite & $\begin{array}{l}51.7001 \\
51.683\end{array}$ & $\begin{array}{l}-37.4374 \\
-37.4302\end{array}$ & $\begin{array}{l}51.6968 \\
51.7273\end{array}$ & $\begin{array}{l}-37.4392 \\
-37.4432\end{array}$ & 51.7133 & -37.4402 \\
\hline
\end{tabular}




\section{G) Hydrothermal fields and plume locations}

\begin{tabular}{|l|lllll|}
\hline Yuhuang & 49.265 & -37.9385 & & \\
\hline Longqi & 49.650 & -37.783 & 49.73 & -37.79 & $\begin{array}{l}49.66 \\
\text { (Turbidity Anomaly) }\end{array}$ \\
\hline
\end{tabular}

\section{References cited in Data Repository:}

Chen, H., Tao, C., Revil, A., Zhu, Z., Zhou, J., Wu, T., and Deng, X., 2021, Induced Polarization and Magnetic Responses of Serpentinized Ultramafic Rocks From Mid-Ocean Ridges: Journal of Geophysical Research: Solid Earth, v. 126, doi:10.1029/2021JB022915.

Li, Y., and Oldenburg, D.W., 1996, 3-D inversion of magnetic data: GEOPHYSICS, v. 61, p. 394408, doi:10.1190/1.1443968.

Maffione, M., Morris, A., Plümper, O., and van Hinsbergen, D.J.J., 2014, Magnetic properties of variably serpentinized peridotites and their implication for the evolution of oceanic core complexes: Geochemistry, Geophysics, Geosystems, v. 15, p. 923-944, doi:10.1002/2013GC004993.

Oufi, O., 2002, Magnetic properties of variably serpentinized abyssal peridotites: Journal of Geophysical Research, v. 107, p. 2095, doi:10.1029/2001JB000549.

Szitkar, F., and Murton, B.J., 2018, Near-seafloor magnetic signatures unveil serpentinization dynamics at ultramafic-hosted hydrothermal sites: Geology, v. 46, p. 1055-1058, doi:10.1130/G45326.1.

Zhdanov, M.S., 2015, Inverse theory and applications in geophysics: Elsevier, v. 36. 